\title{
Plausible Argument in Everyday Conversation
}

\author{
BY Douglas Walton
}

Albany: State University of New York Press, 1992. Pp. xiii + 320. ISBN 0-7914-1157-5, Hardcover, US \$59.50; ISBN 0-7914-1158-3, Paper, US \$19.95.

\section{Reviewed by James B. Freeman}

This book presents a number of themes which are already familiar from Douglas Walton's writings - the centrality of dialogue analysis in understanding and evaluating arguments, types of dialogue and dialogue shifts, the application of this to understanding fallacies. However there are two themes on which I shall concentrate in this review: Walton's emphasis on the functional, pragmatic approach to the analysis and evaluation of both argument and reasoning.

Walton characterizes plausible or presumptive reasoning as "default or defeasible reasoning - a tentative kind of reasoning that is inherently subject to correction, revision, or rebuttal" (xii). Presumptive reasoning is tentative in at least two ways. First, the premises put forward are not known to be true. The respondent in a dialogue agrees to accept the premises tentatively in order to advance the dialogue. The proponent or speaker in the dialogue agrees to withdraw the premises should the respondent introduce new counterevidence into the dialogue. Secondly, presumptive reasoning is tentative in inferring conclusions from premises. Walton highlights the difference this way: Where deductive reasoning may involve a premise that all $\mathrm{F}$ are $\mathrm{G}$ and inductive reasoning a premise that most $F$ are $G$, presumptive reasoning involves a premise that typically F's are G's. If something is an F, then we may take it to be a $G$, until or unless we get information that it is an exceptional case.

Walton characterizes a presumption as a speech act between an assumption-a statement put forward hypothetically so as to draw out its consequences, as in conditional or reductio ad absurdum proofs-and a categorical assertion. One does not put forward an assumption for acceptance and so one incurs no burden to give evidence for it. Likewise, since the purpose of putting the assumption forward is to draw out its logical consequences, and this is not affected by whether the assumption is true or false, evidence against the assumption does not constitute grounds for withdrawing it. In putting forward an assertion, one does encounter a burden of proof, and negative evidence can mandate its retraction. For Walton, presumptions can be put forward without positive evidence, at least without sufficient positive evidence to justify acceptance. In the light of negative evidence, however, presumptions may have to be relinquished.

(C) Informal Logic Vol. 18, Nos. $2 \& 3$ (1996): p-p 
I find this notion of presumption problematic. Now it is a commonplace that in any argument, some premises at least will be put forward without evidence-at least evidence in the form of propositions which support those premises. Otherwise we get into an infinite regress. The question is: Just when can one put forward a premise without evidence? When is one justified in simply accepting a claim without argument? That is, when can we say that there is a presumption in favor of some claim? In certain special contexts, legal disputation being the paradigm example, presumptions are fixed by fiat.' But surely, if two individuals are discussing some issue in an attempt to arrive at the truth of the matter - or at the very least to advance toward that truthcertainly their presumptions should not be a matter of some arbitrary decision. They need epistemological as opposed to legal presumptions, which will not be a simple matter of choice. Walton, by contrast, seems to make presumption almost a matter of niceness or cooperative attitude of the participants in a dialogue towards each other. For a proponent to advance a proposition in the form of a presumption means that instead of her "having to prove the proposition if challenged, the respondent now has the positive obligation to disprove it (by bringing forward evidence) if he cares to challenge it" (40). But where does the proponent get her presumptions? How, in fact, can she even do this without the respondent agreeing to regard them as presumptions, to afford her the license to put forward these statements as presumptions? What is the source of this obligation for the respondent? Is it simply a matter of the respondent's good will? In effect, he is barred from asking the simple question "Why?" But why should he be barred from asking this question, especially should the proponent put forward some highly controversial claim? Walton says, "The function of presumption is to facilitate the progress of the dialogue, when otherwise it could not go ahead to address a practical problem or controversial issue" (40). But if this allows the introduction of highly controversial premises while barring requests for their supporting evidence, how would such a dialogue mark any sort of resolution of the issue? What constrains a respondent not to ask for evidence? What constrains him to accept the claim unless and until he has good reason to reject it?

From his discussion, we may surmise that Walton would answer this question by saying that there was "some procedural reason to accepting the proposition (at least provisionally). It will facilitate the subsequent course of the discussion." (46) To this we ask: Is this all there is to presumption? Walton might reply that these procedural reasons will stem from "agreements made or tacitly accepted at the opening stages of argumentation." (46) But are the participants in a dialogue free to make any agreements they might like to make? If they are, then just about anything could be a presumption, given the right choice of rules. Given the right choice, what is to prevent a proponent from saying "I presume that slavery is morally acceptable; correct me if I'm wrong." "I presume that the holocaust never happened; correct me if I'm wrong." If the concept of presumption is broad enough to accommodate such examples, given a context of dialogue, one wonders what normative force the concept has. 
Walton attempts to give the concept some normative force when he introduces the notion of strengths of presumptions. He distinguishes required, reasonable, and permissible presumptions. A required presumption is one which "must be accepted in every dialogue or situation of the type in question, unless it can be shown that the case in question is exceptional" (50-51). A reasonable presumption is "one that can be accepted as a proposition that is normally found or reasonably expected in this type of situation or dialogue, in the absence of exceptional circumstances." (51) A permissible presumption is one that "the respondent has a choice of whether to accept...or not." (51) Do these characterizations give normative force to the concept of presumption? All are problematic, especially in the light of Walton's previous discussion. The characterization of permissible presumption contradicts Walton's previous characterization of presumption as one which the respondent is obliged to accept unless he has a good reason against it. Walton's example of a required presumption is "If you don't know whether a weapon is loaded or empty, always act on the presumption that it is loaded." Although this illustrates requirement, it is totally obscure to me how it relates to a dialogue or how it becomes a required presumption in the light of the constitutive rules of a dialogue, or whether its being a required presumption transcends any constitutive rules or agreements of a particular dialogue. All this would need to be explained if we were to have a theoretical understanding of required presumption here.

As an example of a reasonable presumption, Walton offers the inference from the premise that John's hat is on the peg to the conclusion that he has not left the house. What is presumed here is the warrant which licenses the inference. This "is based on normal expectations from what the speaker knows about John's habits" (52). Admittedly, this does put presumption on a factual basis to secure its normative force. But if the respondent knows nothing about John's habits, why should he be forbidden to ask why the premise is relevant to the conclusion, and ask for evidence or other assurance of the reliability of the warrant when once presented? What gives the speaker the right to demand such acceptance without evidence? Why should such a requirement be built into the constitutive features of a dialogue? We can ask this same question for the six kinds of warrant for making a presumption which Walton presents-facilitating action, accepted procedures, expert opinion, fashions and customs, conventional wisdom, and cooperation and politeness. For example, if a speaker knows that expert opinion endorses some proposition but the respondent does not, why nonetheless is the respondent required to accept the opinion unless he can refute it? It thus appears that there are serious theoretical difficulties with Walton's notion of presumption. If he is to complete his project, he must develop in detail how presumption is determined by the constitutive rules of dialogue, how such rules will always ground required presumptions and how they will ground reasonable presumptions. If a respondent is required to grant certain presumptions given the defining rules of a dialogue, are such dialogues "interesting"? Why should one want to study dialogues with such mandates? 
Before turning to Walton's functional theory of argument, we want to examine a very novel emphasis in his exposition of dialogue theory in this book. Walton devotes a whole chapter to eristic dialogue, in particular the quarrel. He feels it is important to recognize this type of dialogue for determining and evaluating fallacies. We shall consider Walton's view of the fallacies later in this review. However-and this may seem surprising-Walton feels that the quarrel itself has valuable functions. The first is to substitute verbal activity for physical combat. In particular this verbal activity can have a cathartic effect, releasing emotions which otherwise could operate in harmful ways. The upshot of such consequences could involve serious harm, to oneself or others, "assaults, suicides, or other forms of injury that can never be retracted without permanent or persistent serious effects. By contrast, a quarrel can be "made up"' (141). I, for one, really wonder whether this is too optimistic a view for the sequelae of quarrels. Indeed, I find some of Walton's positive comments about the quarrel quite unpersuasive. He claims that the quarrel is the appropriate place to bring up issues of a highly sensitive nature in an interpersonal relationship. The quarrel, with its lowered inhibitions, allows these issues to come up. But is this going to be constructive? A quarrel over such issues could seriously and permanently damage a relationship. Nor do I see it to be necessary to bring these issues or grievances to light in a quarrel, as Walton does. Why can there be no civil, tactful, diplomatic discussion of these grievances? To his credit, Walton admits that quarrels can have bad outcomes, increasing not overcoming estrangement between the parties. Much depends on how the parties reconcile. Although Walton admits this, his appraisal of the quarrel still seems to me overly optimistic.

Walton's "functional theory of argument" is "designed to make possible the coherent and systematic development of a practical (applied) logic that can be used to evaluate arguments as correct or incorrect in a particular case" (161). Since his theory is functional, Walton insists on going beyond the standard textbook account which sees an argument as a set of statements where one is put forward as supported by others. Rather, Walton cites with approval van Eemeren and Grootendorst's concept of "dialectification of the concept of argument, thinking of an argument as an entity that always has two sides, the pro and the contra" (165). It is an easy step-from this to thinking of argument as something that occurs in dialogue, an exchange typically between two persons, a speaker and a hearer. These persons may enter into the dialogue for all sorts of reasons, to resolve some difference of opinion, prove or disprove some conjecture, formulate some course of intelligent action. (These are just three of twelve possible goals of dialogue that Walton presents on p. 95.) The reason for entering a dialogue will determine the goal of the dialogue. We should evaluate argument with respect to the dialogue in which it appears. Good arguments will advance the goal of the dialogue. Bad arguments will hinder it.

Walton admits that not all arguments occur in dialogue. A categorical syllogism is an argument because its two premises are put forward to support its conclusion. But a syllogism by itself simply does not give us the information to reconstruct a dialogue 
of which we could say this is the dialogue in which the syllogism occurred. In effect, Walton is recognizing the argument as product versus argument as process or procedure distinction other authors have made. Nonetheless, Walton does maintain that all "interesting" argument occurs in dialogue. He contends that: "In practice, an argument would not be useful, nor would it be useful to criticize it as a significant claim upon anyone's assent, unless the argument was also part of a dialogue" (166). One can certainly question why this is the case. Suppose I am wondering whether to accept a claim. I examine reasons supporting that claim. That is, I examine arguments as products from these reasons as premises to the claim as conclusion to see whether they give me good reasons to accept the claim, reasons which are epistemologically acceptable and which are logically adequate in some semantic sense, albeit ordinarily wider than deductive validity. If the reasons were good, why wouldn't the conclusion and the argument as a whole make a claim upon my assent, even if I had no idea of any context of dialogue in which the arguments may have been generated? Or have I generated a context of dialogue by considering these arguments with a view to accepting this claim? Hence, I simply do not see that Walton has made his point that "practically speaking, all argument involves dialogue" (166).

Walton's considerations on the context of dialogue for argument analysis are more persuasive. Although he does not give examples to support his point, his claim seems plausible that we need to consult the textual and dialogical context of an argument to identify properly suppressed premises or conclusions, the inference rules and even just exactly what is the argument.

As dialogue for Walton is the context of argument, argument is the context of reasoning. Walton sees three main ways reasoning is used in argument--probative, hypothetical, and provisional. These "can also be called, derivatively, uses of argument" (177). In probative reasoning, the proponent seeks to move from premises to a specific conclusion, seeking to secure commitment from the respondent both to the premises and to each inferential step leading to the conclusion. Hypothetical reasoning is reasoning from suppositions. The proponent needs to secure commitment only to the inferential steps, not to the premises. I cannot agree without qualification with Walton's claim that such reasoning tends to go anywhere-that a proponent makes assumptions just to see where they will lead. In conditional arguments, for example, the proponent is seeking to establish a certain conditional statement, reasoning from the assumed antecedent to the consequent of the conditional. The whole argument, then, becomes the reason for the conditional statement as conclusion.

Since I have problems with Walton's account of presumption, I have problems with Walton's account of the provisional use of reasoning in argument, for this use is reasoning from premises which are presumptions. Walton says that " $[t]$ his is a mixed function of argument that ranges between the probative function and the hypothetical function.... The hypothetical function is pure supposition, as opposed to the provisional function, which is mixed supposition" (178). Walton simply has to make clear 
what he means here. What is it for presumption to include mixed supposition? There is a standard epistemological presumption in favor of sense perception. Hence we would expect there to be a presumption for a premise which is a perceptual judgment. Where is there any supposition in this-mixed or otherwise? Walton's whole discussion of the distinction between these three types of reasoning seems vague and metaphorical. He has failed to give a clear account of the provisional use of argument or to distinguish it from the clearly distinguishable probative and hypothetical uses.

What then of argument for Walton? "Argument is best defined as reasoning directed toward fulfilling an obligation in a context of dialogue" (184). Walton sees this definition as pragmatic, dialectical, and relativistic. "An argument is correct (good, reasonable, successful) insofar as it fulfills a goal of dialogue and is used rightly and constructively toward that end. An argument that falls short of such a function is weak or faulty, and open to criticism. An argument that blocks, hinders, or strongly deviates from such a function is fallacious or erroneous" (185). But it is obviously open to someone to object: What of an argument occurring in the context of a dialogue whose goal is to reason by semantically invalid steps, such as the fallacies of affirming the consequent, denying the antecedent, undistributed middle, and especially equivocation? Suppose the goal of the dialogue is to pull the wool over people's eyes and dupe them into accepting the conclusion. Are such arguments good? If they are good relative to the goals of the dialogue, what makes that concept of goodness interesting, of normative value?

Walton seeks similarly to relativize the evaluations of reasoning. He understands reasoning from the logical point of view "as a sequence of inference steps from some points (premises) to other points (conclusions)" (203). "Reasoning is normally directed, in a context of argument, toward some goal" (204). "This goal gives the sequence of reasoning its purpose. The reasoning should be judged as good, appropriate, erroneous, fallacious, etc., insofar as it supports the realization of this goal or prevents it from being fulfilled" (205). Reasoning occurs in argument and argument occurs within dialogue. As the goals of a dialogue form the framework for evaluating argument, so the goal of the argument-which could be to establish some proposition-sets the framework for evaluating the reasoning. But suppose the argument occurs within a dialogue whose goal is to establish the conclusion by fallacious arguments and the warrants which the reasoning uses to advance to its goal are semantically fallacious. Are we to call this good reasoning? If so, then what normative interest is left in the concept of good reasoning?

Although Walton's discussion of circular reasoning is not central or essential either to his exposition of presumption or his functional theory of argument, I find errors within his discussion so significant that I must lodge a protest. Walton claims that in some cases circular reasoning can be acceptable. He cites mathematicians' practice of showing that proposition $A$ can be derived from $B$ and then that $B$ can be derived from $A$. But this is not circular reasoning and bears only a certain resemblance to circular reasoning. What mathematicians are showing by this (and in general 
by "daisy chain" reasoning) is not either propositions $A$ or $B$ but the logical equivalence of $A$ with $B$. That equivalence is being established on the basis of arguments which reason hypothetically from $A$ to $B$ and from $B$ to $A$. Once we see the proposition the argument is seeking to establish, we see that there is no circular reasoning here. A second example of circular reasoning Walton considers involves not an argument but an explanation. An economist explains why there is a recession by saying that people are leaving the state. And people are leaving the state because the economy has been poor. Even as an explanation, this has only the appearance of circularity. One economic condition is not being explained in terms of itself. The poor state of the economy is contributing to its worsening, to later states of the economy which are worse, but one state of the economy does not cause itself. Some causal claims involve feedback systems, but this does not involve circularity. One event does not cause a later event, which causes the earlier event. Suggesting that to acknowledge causal feedback is to countenance or engage in circular reasoning betrays confusion. ${ }^{2}$

Walton is concerned to bring out the implications of his functional theory of argument for understanding fallacies. He feels that we need to re-examine a number of patterns of argument which have traditionally been dismissed as fallacious. He regards many instances of these patterns as not fallacious and not even erroneous arguments, but rather as weak or presumptive. For Walton, a type of argument is a fallacy when it "is open to reasonable criticism as a serious failure," yet deserves to be specifically identified since it constitutes a distinctively persuasive or effective technique of argumentation (237). From the functional point of view, a fallacy "can be modelled as a serious abuse of a proper technique of argumentation in a collaborative, goal-directed context of dialogue" (239). The fallacy constitutes a serious abuse because it goes against the overall or collective goal of the dialogue. Arguments, then, are not fallacies outright but only in relation to a context of dialogue and its goals. "An argument that is appropriate in a quarrel may be highly inappropriate and incorrect in a critical discussion" (240). The persuasive force of the fallacy and its constituting a serious abuse are closely related. The persuasive force gives the person advancing the fallacy an unfair strategic advantage, one which in effect "shuts up" the opponent in dialogue, not letting that person make the proper contribution to advance the dialogue toward its goal.

To understand more clearly just what this characterization involves and to bring out the tensions it may conceal, let us consider some of Walton's analyses of particular fallacies. He begins by examining an argument which would traditionally be classified as a you-too or circumstantial ad hominem. A parent argues that his child should not smoke because smoking is unhealthy. The child dismisses the argument out of hand because the parent himself smokes. Walton allows that the circumstantial ad hominem can be defined this way: "Proposition $A$ is incompatible with an arguer's commitments, therefore proposition $A$ is false" (247). Given this definition it looks like we can show that there is a fallacy here. The child rejects the parent's conclusion because it is pragmatically incompatible with the parent's smoking. The parent does 
not practice what he preaches. "This is a fallacy because it does not follow that the parent's conclusion must absolutely be false" (248). But wait-this analysis of the fallacy seems to disregard completely Walton's functional approach. Is this a pragmatic or semantic criticism of the child's argument? In both the definition of the fallacy and in this analysis, I find no reference to context of dialogue or gaining unfair strategic advantage in dialogue. If that is what it is to be a fallacy, then why are not those conditions brought to bear in showing that this argument (under this interpretation at least) is a fallacy? I find a distinct gap between Walton's theory and his particular analysis here. When Walton says that fallacies are arguments open to serious criticism, does he mean semantic criticism or pragmatic, functional criticism? According to his theory, he should mean the latter. According to his practice, he seems to adopt the former, at least in this example.

Walton continues that we could interpret the child's argument in a weaker way. The child is not rejecting the argument but challenging "the parent's personal advocacy of his own argument" (248). This is not a fallacious ad hominem argument, but a reasonable questioning of the parent's trustworthiness at least on this occasion. The problem is that the child has replied to the parent "You smoke yourself. So much for your argument against smoking" (246-47). I do not see how this text is open to the weaker interpretation. Of course, if we had more information about the context, textual or dialogical, we might give a different interpretation of the conclusion. But we do not have that in this case, and it would seem we need to judge from what we have.

We must also press a further point. Suppose the child is asking whether the parent is giving reliable testimony. Intuitively, it would not seem fallacious to raise that question. But could raising that question contradict some goal of some type of dialogue in a way to give an unfair strategic advantage? If so, then according to Walton's view, we would have a fallacy here (although not perhaps an instance of the circumstantial ad hominem). What is bothersome is Walton's suggesting that fallacies are relational concepts, where the context of dialogue is one parameter of the relation, and then speaking as if fallacies can be defined and identified without reference to that parameter. We may agree with Walton that it seems legitimate to raise questions of a proponent's trustworthiness, except perhaps in scientific inquiries (but does not the question arise here also, since we must trust scientists to report their data accurately and scientists must trust their data gathering mechanisms). But from Walton's point of view, doesn't this legitimacy always have to be understood with respect to a context of dialogue?

Walton's analysis of fallacies as uses of arguments, which are in themselves legitimate, to gain an unfair strategic advantage fits especially well with the argumentum ad verecundiam. There need be nothing wrong, per se, in appealing to an authority. However, when an authority is invested with such dignity that "any attempt to question this appeal would be immodest" (259), we have a fallacy. "The tactic is a kind of aggressive use of the appeal to expert opinion to try to quash any attempts to raise critical questions" (259). But again, notice that this appraisal is made without refer- 
ence to the context of dialogue. Is it the case that in all dialogues, the respondent is supposed or allowed to raise critical questions in order to advance the goals of the dialogue? This may be true in critical discussions and inquiries, but what about quarrels? Are ad verecundiam arguments fallacious in quarrels?

In some ways, there is something quite correct in what Walton has to say about the patterns of inference he discusses in connection with the fallacies. As ways of shifting burden of proof, these patterns are legitimate, both the ad hominem and ad verecundiam we have considered and the ad ignorantiam, which Walton also discusses. If someone does not practice what he preaches, it may be legitimate to shift the burden of proof onto him to re-establish his trustworthiness. In the absence of rebutting evidence, the burden of proof may be on someone to show why we should not accept a proposition, why there is not a presumption for it. That is, presumption holds ad ignorantiam, in ignorance of rebutting or refuting conditions. If an expert endorses a view, the burden of proof is on the respondent who would reject that view to show why. Where fallacy enters is in unwarrantedly maintaining that this burden can in no way be discharged and in striving to silence the respondent when he attempts to discharge it. This is an illuminating comment on the fallacies. But notice that this discussion is not relativized to context of dialogue, although it is describing situations which can arise in dialogue. It is not at all clear how the type of dialogue we are dealing with enters into the determination of fallaciousness or non-fallaciousness.

We are thus unpersuaded of Walton's account of argument evaluation. His final remarks on the subject in the last chapter of the book do not change our assessment. As he there outlines it, evaluation begins by analysing a text allegedly containing argumentation, identifying premises and conclusion. The next step is to bring forward "a normative model, a structure that stipulates, in a broad and general way, what the requirements are that the particular argument must meet in order to be a successful argument of that type" (287). But how is one to know what model to bring forward? Walton himself admits that this can be problematic in many instances. For these, we can only give conditional evaluations. If this is the type of dialogue the participants are engaged in, then these moves are good because they advance the goals of the dialogue and those are bad because they retard it. To some, this will seem practically to abandon argument evaluation. And it will be to abandon it if there are objective semantic and epistemological criteria for evaluating arguments. For there is no guarantee that these criteria will be satisfied by the rules of a dialogue. What is distinctly problematic is that Walton discusses these rules in the abstract. We do not see concrete sets of rules by which to construct and evaluate arguments, and whose correctness (or lack of it) might be evident. Again, as we have seen, Walton seems to waffle back and forth between his relativistic, pragmatic theory and applying non-relativistic standards in the evaluation of particular arguments. He seems prepared to criticize arguments as fallacious without inquiring about the kind of dialogue in which they occur. This may be because he is operating on the assumption that "When it comes to the analysis of fallacies, the main type of dialogue that should come into 
play as a normative model is the critical discussion" (289-90). But given Walton's explicitly relativistic stance, is he allowed to make that assumption?

Since we have been quite critical in this review (and we could raise further points of criticism), we want to close by pointing out what we find of especial positive value in Walton's essay, and how this may be separated or disentangled from what makes the study problematic. First, the concept of presumption should be central in argumentation theory. We fully agree with Walton that many of the premises from which we reason in everyday conversation, both with ourselves and with others, are presumptions and by reasoning properly from such premises, by presumptive warrants, we may transfer such presumptions to conclusions in order to show them acceptable. We fully agree with Walton that these presumptions are defeasible, and that at some later point in the dialogue they may (need to) be withdrawn. What we reject is the notion that presumptions are somehow subjectively, relativistically, or voluntarily determined. We reject the view that a proponent can simply designate a proposition as a presumption or may obtain presumption status for a proposition by use of a special speech act. Presumption, as we see it applying to evaluating arguments aimed at arriving at the truth about some issue, is inherently connected with source reliability or the proper functioning of belief-generating mechanisms. Nicholas Rescher makes this point in both Dialectics and in Plausible Reasoning - seminal works for developing a philosophical understanding of presumption. Any account of presumption needs to make contact with this material and build upon it.

We also find much value in Walton's pointing out that there may be a maieutic closure of dialogue. A dialogue may not close with bringing an issue to resolution; there may be no "winner" whose point is conceded by the other participant. Yet if the dialogue has enabled the participants to see more clearly the roots of their disagreement, how that disagreement involves a divergence on certain fundamental issues, the dialogue itself has had positive value. I think this is a very important contribution for appreciating the value of argumentation in public life. Disagreements over issues may involve disagreements over values. To insist that one person be prepared to change, modify, or abandon certain of his or her core values on the basis of a course of argumentation strikes me as setting up a mechanism to get power over someone, not to enable that person to function as a critical agent. Our values are intimately connected with who we are and how we function in the world. One needs to treat a person's values with respect. If engaging in dialogue can bring one's deep value commitments to light, if it can reveal deep value disagreement, it can have a profound positive effect on how we can get along with each other in a pluralistic society. To see a position as based on certain fundamental values may allow those not holding the position to nonetheless view it and those who do hold it with respect. To bring about agreement on certain issues, we may need to bring about profound value resolution. If that is not possible, we may, as a matter of humanity and civility, have to agree to disagree. Our society is marked by profound disagreements in morals and public policy -the moral status of the unborn, the meaning 
of sexuality and gender differentiation, the permissibility of euthanasia - of such poignancy as to constitute what some call a "culture war." Being able to bring the most fundamental value disagreements which underlie these issues to light through dialogues which come to maieutic closure may be necessary for us all to live together. The theory and practice of dialogue may be essential to public philosophy and indeed to public life itself. ${ }^{3}$

\section{Notes}

${ }^{1}$ The presumption is not thereby arbitrary. That a person is presumed innocent until proven guilty reflects a distinct evaluation, a preference for individual rights and liberties over the common peace. It is more tolerable to risk a criminal presence in society with its attendant liabilities than to unjustly deprive someone of life, liberty, or property.

${ }^{2}$ This point is brought out nicely in Wesley Salmon's Logic.

${ }^{3}$ I want to thank Jonathan $E$. Adler for useful comments on an earlier draft of this review.

JAMES B. FREEMAN

DEPARTMENTOF PHILOSOPHY HUNTER COLLEGE/CUNY 